\title{
Testosterone-Induced Matrix Metalloproteinase Activation Is a Checkpoint for Neuronal Addition to the Adult Songbird Brain
}

\author{
Dae-Hee Kim, ${ }^{1 \star}$ Christina Lilliehook, ${ }^{1 \star}$ Breana Roides, ${ }^{1}$ Zhuoxun Chen, ${ }^{1}$ Mayland Chang, ${ }^{2}$ Shahriar Mobashery, ${ }^{2}$ and \\ Steven A. Goldman ${ }^{1}$ \\ ${ }^{1}$ Department of Neurology, University of Rochester Medical Center, Rochester, New York 14642, and 2Department of Chemistry and Biochemistry and the \\ Walther Cancer Research Center, University of Notre Dame, Notre Dame, Indiana 46556
}

\begin{abstract}
Testosterone-induced neuronal addition to the adult songbird vocal control center, HVC, requires the androgenic induction of vascular endothelial growth factor (VEGF), followed by VEGF-stimulated angiogenesis. The expanded vasculature acts as a source of BDNF, which supports the immigration of new neurons from the overlying ventricular zone. In tumorigenesis, a similar process of adult angiogenesis is regulated by matrix metalloproteinase (MMP) activity, in particular that of the gelatinases. We therefore investigated the role of the gelatinases in neuronal addition to the HVC of adult female canaries. In situ zymography of the caudal forebrain revealed that testosterone-induced perivascular gelatinase activity that was most prominent in HVC. High-resolution gels revealed distinct MMP activities that comigrated with MMP2 and MMP9, and PCR cloning yielded MMP2 and MMP9 orthologues of 1465 and $1044 \mathrm{bp}$, respectively. Quantitative PCR revealed that HVC MMP2 mRNA levels doubled within $8 \mathrm{~d}$ of testosterone, whereas MMP9 transcript levels were stable. Moreover, isolated adult canary forebrain endothelial cells secreted MMP2, and VEGF substantially increased endothelial MMP2 gelatinase activity. To assess the importance of androgen-regulated, VEGF-induced MMP2 to adult angiogenesis and neurogenesis, we treated testosterone-implanted females with the gelatinase inhibitor SB-3CT. In situ zymography confirmed that SB-3CT suppressed gelatinase activity in HVC, and histological analysis revealed that SB-3CT-treated birds exhibited a decreased endothelial mitotic index and substantially diminished neuronal recruitment to HVC. These data suggest that the androgenic induction of endothelial MMP2 is a critical regulator of neuronal addition to the adult $\mathrm{HVC}$, and as such comprises an important regulatory step in adult neurogenesis.
\end{abstract}

Key words: adult neurogenesis; angiogenesis; matrix metalloproteinase; songbird; neuroplasticity; gonadal steroid; canary

\section{Introduction}

In the adult avian brain, neurogenesis persists in several regions of the forebrain responsive to gonadal steroids, including the vocal control nucleus HVC (Goldman and Nottebohm, 1983; Alvarez-Buylla, 1992; Nottebohm, 2002). In adult canaries, testosterone-induced neurogenesis is preceded by an upregulation of vascular endothelial growth factor (VEGF), which acts via its receptor VEGFR2/KDR/quek1 to stimulate mitotic expansion of HVC capillaries (Louissaint et al., 2002a). The expanded endothelial cell population then serves as a source of secreted BDNF, which acts to support the survival and integration of neurons newly recruited from the overlying ventricular zone. Angiogenesis during both brain development and tumor invasion is

\footnotetext{
Received Aug. 13, 2007; revised 0ct. 8, 2007; accepted Nov. 12, 2007.

This work was supported by National Institute of Neurological Disorders and Stroke Grant R37/R01NS29813 and the G. Harold and Leila Y. Mathers Charitable Foundation (S.A.G.) and by National Cancer Institute Grant CA122417 (M.C., S.M.).

${ }^{*}$ D.-H.K. and C.L. contributed equally to this study.

Correspondence should be addressed to Dr. Steven A. Goldman, Department of Neurology, University of Rochester Medical Center, 601 Elmwood Road, Box 645, Rochester, NY 14642. E-mail: steven_goldman@ urmc.rochester.edu.

DOI:10.1523/JNEUROSCI.3674-07.2008

Copyright $\odot 2008$ Society for Neuroscience $\quad$ 0270-6474/08/280208-09\$15.00/0
}

facilitated by the activity of members of the matrix metalloproteinase (MMP) family, particularly the gelatinases MMP2 and MMP9 (Bergers et al., 2000).

Given the importance of MMP activity in angiogenesis, we investigated the activation of the matrix metalloproteinases in the testosterone-treated adult female canary brain. In situ zymography revealed that testosterone treatment presaged a sharp increase in HVC gelatinase activity, which was localized to the microvascular endothelium. High-resolution gels of isolated canary forebrain endothelial cells (CBECs) then revealed two distinct MMP activities, which comigrated with human recombinant MMP2 and MMP9. Quantitative PCR (qPCR) analysis of testosterone-stimulated HVC revealed that MMP9 mRNA levels were unaltered, whereas MMP2 mRNA levels doubled within $8 \mathrm{~d}$ of testosterone treatment. To determine the importance of MMP2 activation to testosterone-induced neuronal recruitment, we then administered the MMP2/9 inhibitor SB-3CT to testosterone-treated birds. SB-3CT is a gelatinase-specific thiirane inhibitor of MMP2 and MMP9, which undergoes a complex transformation within the active sites of these enzymes that leads to their potent and selective inhibition (Brown et al., 2000). It has exhibited no evident systemic toxicity and excellent CNS penetrability; in vivo, SB-3CT has been shown to rescue laminin 
from proteolysis in vivo after transient cerebral ischemia ( $\mathrm{Gu}$ et al., 2005), indicating its efficacy in suppressing MMP9-associated matrix degradation in the adult brain. We found that when delivered after testosterone treatment, SB-3CT substantially suppressed both angiogenesis and neurogenesis in $\mathrm{HVC}$, indicating a critical need for androgen-induced MMP activity in both microvascular expansion and neuronal addition. In addition, we noted that MMP2 was secreted from HVC endothelial cells in response to VEGF, but not to testosterone, indicating that testosteroneinduced MMP activation is mediated through androgen-induced VEGF. These observations identify the induction of endothelial MMP2 as a critical regulatory step permitting the successful recruitment and integration of new neurons into the adult forebrain.

\section{Materials and Methods \\ Animals}

One-year old female canaries were obtained from our breeding colony at the University of Rochester Medical Center (URMC). Canaries were housed under full-spectrum fluorescent lighting using the natural light cycle throughout the year. Testosterone induction was performed only during periods of increasing light:dark ratio, typically beginning at 12-13 $\mathrm{h}$ light:11-12 h dark. The care and use of the birds was performed according to National Institutes of Health guidelines and was reviewed by the University Committee on Animal Resources of URMC. For testosterone induction, we implanted 8-mm-long SILASTIC tubes, either filled with testosterone propionate (T-1875; Sigma, St. Louis, MO) or empty, subcutaneously over the pectoral musculature, as described previously (Goldman and Nottebohm, 1983; Louissaint et al., 2002).

\section{In situ zymography}

In situ zymography was performed as previously described (Frederiks and Mook, 2004). In brief, freshly frozen brains embedded in optimal cutting temperature medium (OCT) were cut in $14 \mu \mathrm{m}$ sections and collected on Superfrost slides. Sections were briefly rehydrated in PBS and then incubated with substrate gelatin solution [50 mM Tris- $\mathrm{HCl}, \mathrm{pH}$ $7.5,150 \mathrm{~mm} \mathrm{NaCl}, 5 \mathrm{~mm} \mathrm{CaCl}_{2}, 0.2 \mathrm{~mm} \mathrm{NaN}_{3}, 1 \%$ (v/v) polyvinyl alcohol, $20 \mu \mathrm{g} / \mathrm{ml}$ Oregon Green 488-conjugated gelatin (Invitrogen, Carlsbad, $\mathrm{CA})$ ] for $3 \mathrm{~h}$ at $37^{\circ} \mathrm{C}$ in a humidifying chamber. After incubation, slides were washed with PBS and mounted using Vectashield with $4^{\prime}, 6^{\prime}$ diamidino-2-phenylindole (DAPI) (Vector Laboratories, Burlingame, CA). When assessing gelatinase inhibition, the degree of MMP inhibition was first analyzed by converting raw pictures to the pixel intensity distribution using the surface plot function of ImageJ; quantitative comparison was then accomplished by comparing the pixel intensity distributions of each brain section.

\section{Tissue dissection and HVC sampling}

HVC was dissected from whole canary brains that had been removed from the skull immediately after general anesthesia using sodium pentobarbital (i.m.), followed by transcardiac perfusion with ice-cold HBSS. Dissection was performed following the approximate coordinates of Stokes et al. (1976) and using the rostral tip of the cerebellum as a landmark for anteroposterior 0.0. A dorsal approach was used by which to both identify and then dissect HVC, after removal of the overlying parahippocampus. Paired 4-7 mm microiridectomy blades were used for the actual dissection, with guidance using a Wild operating microscope at $60 \times$. For both gelatinase gel zymography and RNA extraction, HVC samples were typically dissected, removed, and frozen within $15 \mathrm{~min}$ of anesthesia induction.

\section{Gelatinase gel zymography}

Gelatinase extraction and zymography were performed as previously described (Descamps et al., 2002). Tissue samples were homogenized in ice-cold lysis buffer [1\% Triton X-100, 50 mм Tris-HCl, pH 7.6, $150 \mathrm{~mm}$ $\mathrm{NaCl}, 5 \mathrm{~mm} \mathrm{CaCl}_{2}, 0.05 \%$ Brij-35, $0.02 \% \mathrm{NaN}_{3}$, and protease inhibitor mixture (RocheIndianapolis, IN)], clarified $(16,000 \times g$ for $15 \mathrm{~min}$ at $4^{\circ} \mathrm{C}$ ), and stored at $-80^{\circ} \mathrm{C}$ until analysis. Conditioned media was collected from $\mathrm{CBECs}$ and was stored at $-80^{\circ} \mathrm{C}$ until analysis. Sample pro- tein concentration was determined with the BCA assay (Pierce, Rockford, IL). For analysis, $1-20 \mu \mathrm{g}$ of total protein was denatured with a $2 \times$ nonreducing sample buffer (125 mM Tris- $\mathrm{HCl}, \mathrm{pH}$ 6.8, 20\% glycerol, 4\% SDS, $0.003 \%$ bromophenol blue) and resolved on $1.0 \mathrm{~mm} 8 \%$ SDSPAGE gels containing $0.1 \%$ gelatin. After electrophoresis, gels were incubated with rotation for $2 \times 20 \mathrm{~min}$ in $2.5 \%$ Triton at room temperature and developed for $24-48 \mathrm{~h}$ in $50 \mathrm{~mm}$ Tris- $\mathrm{HCl}, \mathrm{pH}$ 7.6, $200 \mathrm{~mm}$ $\mathrm{NaCl}, 5 \mathrm{~mm} \mathrm{CaCl}$, and $0.05 \%$ Brij- 35 at $37^{\circ} \mathrm{C}$. After development, gels were stained in Coomassie brilliant blue, destained, transferred to $3 \%$ glycerol, and photographed. Gelatinolytic activity was quantified using ImageJ. Pixel intensity of each gelatinolytic band was measured by Image J's plot profile function, and the sum of pixel intensities for each band was then compared with other bands. The pixel intensities of bands within each gel was normalized against a common control in each gel.

\section{Endothelial cell isolation and culture}

Adult CBECs were obtained from the dissected forebrain of adult canaries. The birds were perfused with ice-cold HBSS via a transcardiac approach after terminal anesthesia by pentobarbital overdose. The tissue was collected in HBSS, and the forebrain area was dissected out. Isolation and preparation of endothelial cell cultures was performed using our previously described protocol (Leventhal et al., 1999) with further modification. Briefly, the dissected brain tissue was ground with Dounce glass tissue grinder (clearance: $0.711-0.119 \mathrm{~mm}$ ) and resuspended into $18 \%$ dextran solution followed by centrifugation $\left(5000 \times g, 4^{\circ} \mathrm{C}\right)$. The resulting microvascular fragments pellets were resuspended into a dissociation mixture containing collagenase/dispase/DNase and then incubated for $15 \mathrm{~min}$ at $37^{\circ} \mathrm{C}$. Digested vessel fragments were then washed with PBS three times, resuspended in media [M131 (Cascade Biologics, Portland, OR), VEGF (20 ng/ml), basic fibroblast growth factor (bFGF; $10 \mathrm{ng} / \mathrm{ml}$ ), epidermal growth factor (EGF; $10 \mathrm{ng} / \mathrm{ml})$, hydrocortisone $(1 \mu \mathrm{g} / \mathrm{ml})$, heparin $(10 \mu \mathrm{g} / \mathrm{ml})$, and $5 \%$ platelet-depleted FBS], and then plated onto collagen I-coated multiwell plates. Purity of primary endothelial culture was confirmed by flow cytometry on a FACSAria (Becton-Dickinson), based on the uptake of DiI-conjugated acetylated LDL (low-density lipoprotein) as described (Leventhal et al., 1999). To challenge CBECs with agents intended to influence gelatinase expression, cultures were raised in a serum-free base medium of M131 supplemented with bFGF (10 ng/ml), EGF (10 ng/ml), hydrocortisone $(1 \mu \mathrm{g} / \mathrm{ml})$, and heparin (10 $\mu \mathrm{g} / \mathrm{ml})$, to which either VEGF $(20 \mathrm{ng} / \mathrm{ml})$ or testosterone $(100 \mathrm{ng} / \mathrm{ml})$ were added as appropriate.

\section{Degenerate PCR and cloning of canary MMP2 and MMP9 fragments}

Degenerate primers to amplify canary MMP2 and MMP9 fragments were designed based on homology with chicken, turkey, and mouse MMP2 and MMP9 sequences, respectively (MMP2 forward primer 5-TRG CAG TGC AAT ACC TGA A-3, MMP2 reverse primer 5-GCR AAR AAY ACA GCC TTC TC-3, MMP9 forward primer 5-GAT GCY CAY TTY GAT GAT GAT GAG-3, MMP9 reverse primer 5-GGT CCA RTA TTT YCC RTY CTT GA-3). PCR on ovary cDNA template using LaTaq (Takara, Tokyo, Japan) was performed for 35 cycles using the following conditions: $94^{\circ} \mathrm{C}$ for $30 \mathrm{~s}, 51^{\circ} \mathrm{C}$ (MMP2) or $48^{\circ} \mathrm{C}$ (MMP9) for $30 \mathrm{~s}, 72^{\circ} \mathrm{C}$ for 1 min. Amplified fragments were excised from $1 \%$ agarose gels, cloned into the MCS of pCR II-TOPO vector (Invitrogen) and sequenced. A $1471 \mathrm{bp}$ canary MMP2 fragment was obtained that was $91 \%$ identical to chicken MMP2 (NM_204420) and a 1044 bp MMP9 fragment that was $88 \%$ homologous to chicken MMP9 (NM_204667).

\section{RNA extraction and real-time PCR analysis}

Total RNA from pooled bilateral HVC samples taken at 0,4 , and $8 \mathrm{~d}$ post-SILASTIC hormone implantation ( $n=4$ birds/time point) was extracted using Trizol, according to the manufacturer's instructions (Invitrogen). Precipitated RNA was dissolved in RNase-free water (Ambion, Austin, TX) and cleaned over a Qiagen (Valencia, CA) RNeasy column with on-column DNase treatment; the integrity and purity of the RNA was verified using an Experion RNA analysis system (Bio-Rad, Hercules, CA). One nanogram of total RNA from each sample was then reverse transcribed in $50 \mu \mathrm{l}$ reactions using Taqman reverse transcription kit (Applied Biosystems, Foster City, CA), and the resulting cDNA was di- 
luted to $1 \mathrm{ng} / \mu \mathrm{l}$ for real-time PCR analysis. Realtime PCR analysis was performed in $25 \mu$ l PCRs (5 ng of template) with SYBR green on an ABI prism 7000 system. Relative levels of MMP2 and MMP9 transcripts were normalized to glyceraldehyde-3-phosphate dehydrogenase (GAPDH) levels. Primers used in this study were designed based on the sequence information of canary MMP2, MMP9, and GAPDH clones (MMP2 forward primer 5-TGG TCG CTG CCC ATG AAT-3, MMP2 reverse primer 5-GCT CCC GGG TCC TCA GA-3, MMP9 forward primer 5-GGG AAC TGG CTT AGT GGT GAA G-3, MMP9 reverse primer 5-GCA GTG GCC CTC GAA GAT G-3, GAPDH forward primer 5-CCA TCA CAG CCA CAC AGA AGA-3, and GAPDH reverse primer 5-CCT CTG CCA TCC CTC CAA-3).

\section{MMP inhibition}

SB-3CT, a potent thiirane inhibitor of the gelatinases (Brown et al., 2000; Gu et al., 2005), was used to inhibit MMP activity. SB-3CT is a competitive, mechanism-based inhibitor specific for MMP2 and MMP9 $\left(K_{\mathrm{i}}=14 \mathrm{nM}\right.$ for MMP-2 and $600 \mathrm{~nm}$ for MMP-9), which exhibits either no inhibition or very poor inhibition of other MMPs in vitro (Brown et al., 2000). SB-3CT was given parenterally, via single daily intrapectoral injection of $1 \mathrm{mg} / 50 \mu \mathrm{l} / \mathrm{bird}$ (equivalent to 50 $\mathrm{mg} / \mathrm{kg}$, assuming average weights of $20 \mathrm{~g} / \mathrm{ca}-$ nary), as a solution containing $20 \mathrm{mg} / \mathrm{ml} \mathrm{SB}$ 3CT in 20\% dimethylsulfoxide (DMSO)/60\% polyethylene glycol (PEG)-200/20\% water. In pilot experiments, we established that this dose was sufficient to abolish HVC gelatinase activity as assessed by in situ zymography, whereas it yielded no overt signs of toxicity over dosing periods as long as $25 \mathrm{~d}$.

\section{Immunohistochemistry}

Animals were perfused with ice-cold HBSS (Invitrogen), and their brains were removed and fresh frozen in OCT, then cryosectioned coronally at $14 \mu \mathrm{m}$ on a Leica (Bannockburn, IL) $\mathrm{CM} 3050 \mathrm{~S}$ cryostat and stored frozen at $-80^{\circ} \mathrm{C}$. Sections were prepared into 10 series of slides, with three sections on each slide. Sections were rehydrated in PBS and fixed in $4 \%$ paraformaldehyde for 15 min at $25^{\circ} \mathrm{C}$ before immunolabeling.

The borders of HVC. The borders of HVC were defined by estrogen receptor immunostaining. Estrogen receptor- $\alpha$ (ER) expression in the dorsocaudal forebrain is limited to HVC and the adjacent ventricular wall medial to it, allowing HVC's borders to be defined by the spatial extent of ER immunolabeling (Gahr, 1990; Hidalgo et al., 1995). This is especially valuable in defining $\mathrm{HVC}$ in females, in which the borders of HVC are often scarcely identifiable (Fig. 1). In these birds, ERimmunoreactive cells, and hence HVC, were visualized using rat monoclonal anti-estrogen receptor clone H222 $\gamma$ (Ab-21, Lab Vision, Fremont, CA), as described previously (Hidalgo et al., 1995). Briefly, sections were treated with $0.3 \% \mathrm{H}_{2} \mathrm{O}_{2}$ for $15 \mathrm{~min}$, permeabilized with $1 \%$ Triton $\mathrm{X}-100$ for $15 \mathrm{~min}$, blocked by $5 \%$ goat serum for $1 \mathrm{~h}$, and exposed to anti-ER antibody $(1: 100)$ overnight at $4^{\circ} \mathrm{C}$. After washing, sections were serially incubated in biotinylated goat anti-rat IgG (1:100) and Vectastain ABC (Vector Laboratories), with washes after each step, then processed in 0.2 $\mathrm{mg} / \mathrm{ml}$ diaminobenzidine and $0.003 \% \mathrm{H}_{2} \mathrm{O}_{2}$ for $10 \mathrm{~min}$, dehydrated, and mounted in CytosealXYL.

Newly generated HVC endothelial cells. Newly generated HVC endothelial cells were detected by staining for laminin, a vascular marker, and bromodeoxyuridine (BrdU) using double immunofluorescence, as described previously (Louissaint et al., 2002). Sections were denatured in
$2 \mathrm{~N} \mathrm{HCl}$ for $30 \mathrm{~min}$, then permeabilized by $0.1 \%$ saponin for $15 \mathrm{~min}$, blocked by $5 \%$ goat serum for $1 \mathrm{~h}$, and stained for BrdU using rat antiBrdU IgG antibody at 1:100 (Serotec, Raleigh, NC) overnight at $4^{\circ} \mathrm{C}$. After washing, the anti-BrdU primary antibody was detected with FITCconjugated goat anti-rat IgG Fab (1:100), followed by FITC-conjugated avidin (Invitrogen, 1:2000). Visualization of the vasculature was then achieved by exposing the sections to a rabbit anti-laminin IgG (Sigma, 1:100) overnight at $4^{\circ} \mathrm{C}$. After washing, the primary antibody was detected with Alexa Fluor 594-conjugated goat anti-rabbit IgG (Invitrogen, $1: 400)$.

Newly generated neurons. Newly generated neurons were detected by staining for Hu protein, a neuronal marker (Barami et al., 1995), and BrdU using double immunofluorescence. Hu antigen was detected using a monoclonal anti-Hu IgG, 16A11 (Invitrogen), which recognizes the $\mathrm{Hu}$ /Elav family members $\mathrm{HuC}, \mathrm{HuD}$, and Hel-N1 and specifically labels neurons. The antibody was used at a concentration of $10 \mu \mathrm{g} / \mathrm{ml}(1: 50)$. Sections were permeabilized by $0.1 \%$ saponin, blocked by $5 \%$ goat serum for $1 \mathrm{~h}$, and exposed to anti-Hu IgG overnight at $4^{\circ} \mathrm{C}$. After washing, the primary anti-Hu antibody was detected with biotinylated goat antimouse IgG (1:100), followed by a Texas Red-conjugated avidin (Vector Laboratories, 1:50). The sections were then stained for BrdU as described above.

\section{Scoring}

Endothelial labeling indices. To assess testosterone-induced angiogenesis and any treatment-associated inhibition thereof, the brains of 12 birds were cryosectioned at $14 \mu \mathrm{m}$ and apportioned as 10 series comprised of sections taken $140 \mu \mathrm{m}$ apart. The scored 
region of HVC was identified by overlaying images of adjacent sections stained for the estrogen receptor on those of sections stained for BrdU and laminin. For each bird, five to seven sections (10-14 HVCs) were taken at intervals of $140 \mu \mathrm{m}$, which spanned the anteroposterior coordinates anterior 0.0 (A0.0) to posterior 0.6 (P0.6) in the stereotaxic plane, and which thereby included HVC (Stokes et al., 1976). In each HVC, the incidence of lami$\operatorname{nin}^{+} / \mathrm{BrdU}^{+}$cells and the total HVC laminin ${ }^{+}$ECs were manually scored. Total HVC endothelial cells were counted by double labeling laminin-stained sections with DAPI so as to visualize and score individual endothelial nuclei.

HVC neuronal labeling indices. To evaluate testosteroneassociated neurogenesis, the brains of 16 birds were cryosectioned at $14 \mu \mathrm{m}$ in 10 series. HVC was traced by overlaying images of BrdU/Hu-stained sections with adjacent sections stained for the estrogen receptor. For each bird, five to seven sections (10-14 HVCs) were taken at intervals of $140 \mu \mathrm{m}$ spanning the nucleus HVC through the anteroposterior coordinates A0.0 to P0.6 in the stereotaxic plane (Stokes et al., 1976). In each HVC, the incidence of $\mathrm{Hu}^{+} / \mathrm{BrdU}^{+}$cells and the total $\mathrm{HVC} \mathrm{Hu}^{+}$neurons were manually scored. Total HVC neurons were counted by double labeling Hu-stained sections with DAPI so as to visualize and counted by particle-analyzing tool of ImageJ.

\section{Results}

Testosterone-induced MMP activity localizes selectively to HVC and its vascular bed

In situ zymography (Frederiks and Mook, 2004) was first used to assess the presence, and androgenic regulation, of MMP gelatinase activity in the adult HVC. Adult female canaries were implanted with either testosterone-filled or empty SILASTICs and then killed at either 4 or $9 \mathrm{~d}$ thereafter ( $n=3$ birds/time point). The brains were removed, and a segment spanning the approximate stereotaxic coordinates A1.0 to P1.2 was then cut at $14 \mu \mathrm{m}$, and adjacent sections were stained with Nissl stain or immunostained for ER, so as to define the borders of HVC (Gahr, 1990; Hidalgo et al., 1995) (Fig. 1A,B). Alternate sections were then subjected to in situ zymography to localize gelatinase activity. On-slide zymograms revealed that in the dorsocaudal forebrain, testosterone-induced MMP activity was essentially restricted to HVC (Fig. 1C-F). Indeed, only a relatively low level of detectable capillary MMP activity was noted in most of the mesopallium, the region of forebrain in which HVC resides (Reiner et al., 2004; Jarvis et al., 2005). In contrast, prominent MMP activity was detected in the HVC of female birds that were killed $9 \mathrm{~d}$ after testosterone treatment. HVC was clearly delineated by zymography in the testosterone-stimulated females, but was not evident in their empty SILASTIC controls. Moreover, high-power images revealed that within $\mathrm{HVC}$, the MMP signal was entirely restricted to the capillary microvasculature. These observations indicate that testosterone is sufficient to trigger an increase in MMP gelatinase activity in the adult HVC, that this MMP activity is perivascular and distributed through the HVC capillary bed, and that within the mesopallium, androgen-induced gelatinase activity is largely restricted to HVC.

\section{VEGF triggers MMP2 secretion and activation by isolated brain endothelial cells}

We next used gel zymography (Wang et al., 2003) to identify those MMP gelatinases expressed by the HVC microvasculature. In addition, we asked which of these might be testosterone regulated, either directly or by VEGF, its paracrine intermediary in androgen-associated neurogenesis (Louissaint et al., 2002). We

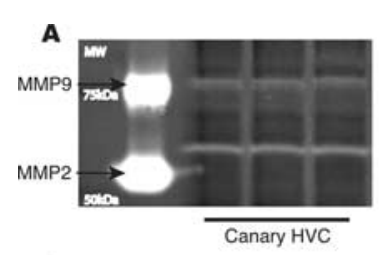

C

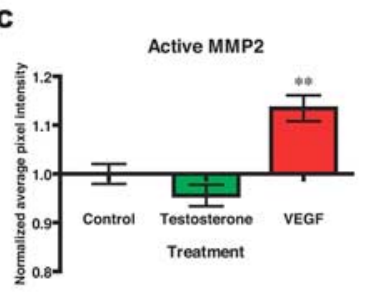

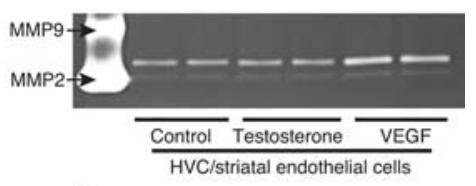

D

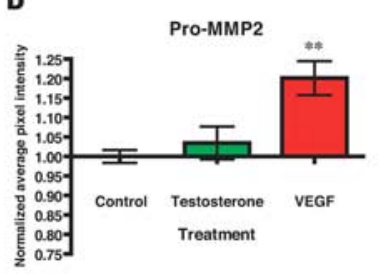

$\mathbf{E}$

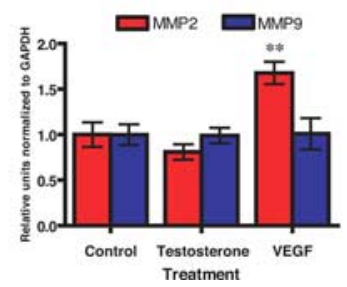

Figure 2. VEGF triggers MMP2 secretion by canary forebrain endothelial cells. $\boldsymbol{A}$, Both proMMP2 and pro-MMP9 gelatinase activities were noted by gel zymography of adult female HVC tissue extracts, taken from birds given testosterone and killed $8 \mathrm{~d}$ after testosterone treatment. These gels were developed briefly, highlighting the gelatinase activities associated with the MMP2 and MMP9 pro- forms, which are both more abundant than their active products, and enzymatically active in denaturing gels like these. $\boldsymbol{B}$, Media from $2 \mathrm{~d}$ serum-free cultures of isolated canary forebrain endothelial cells were analyzed by gel zymogram; $4 \mu \mathrm{g}$ of sample were loaded per well. VEGF exposure induced a significant increment in gelatinase activity; testosterone treatment did not. C, D, Pixel analyses of gel zymograms for active and pro-MMP2. Pixel intensity from different gels was normalized against a common control. $\boldsymbol{E}, \mathrm{RT}-\mathrm{PCR}$ showed that CBECs exhibited increased MMP2 transcript levels in response to VEGF. MMP9 mRNA was also expressed, but exhibited no evident response to VEGF or testosterone. ${ }^{* *} p<0.01$ by ANOVA with Bonferroni $t$ tests.

first assessed MMP gelatinase activity in whole-tissue extracts of testosterone-treated HVC and identified sharp and specific activities corresponding to MMP2 and MMP9 (Fig. $2 A$ ). We next asked whether these activities were specifically associated with HVC endothelial cells, as suggested by the in situ zymography. To this end, we isolated microvascular endothelial cells from canary brain as described previously (Leventhal et al., 1999; Louissaint et al., 2002) and exposed them to potential activators of gelatinase activity. Specifically, after isolation and maintenance in bFGF and EGF (10 ng/ml each), the cultures were exposed for $48 \mathrm{~h}$ to VEGF $(20 \mathrm{ng} / \mathrm{ml})$ or testosterone $(100 \mathrm{ng} / \mathrm{ml})$, or to basal media alone, then extracted and assessed for MMP activity by gelatin zymography. Gelatin zymography was performed on $10 \mu \mathrm{g}$ of protein-extracted lysate from each sample, as described previously (Descamps et al., 2002).

By this means, we found that gelatinase activities comigrating with both the pro- and active forms of MMP2 were present in the extracts. MMP2 activity was dynamically modulated, such that gelatinase activities attributable to both pro- and active MMP2 increased in response to VEGF (Fig. $2 B-D$ ). Indeed, analysis of the imaged zymography bands on the basis of normalized pixel density revealed a significant stimulation of active MMP2 by VEGF, but no such activation by testosterone ( $F=16.2$ by oneway ANOVA; $p<0.01$ by post hoc Bonferroni $t$ test) (Fig. $2 C$ ). Similarly, zymography revealed a significant stimulation by VEGF, but not testosterone, of pro-MMP2-associated gelatinase activity $(F=8.8$ by one-way ANOVA; $p<0.01)$ (Fig. 
$2 D)$. However, despite the sharp VEGF-induced increases in both pro- and active MMP2-associated gelatinase activities, we observed no expression of MMP9 gelatinase activity by CBECs under any condition tested, although MMP9 gene expression was noted by real-time (RT)-PCR (Fig. 2E). These data indicate that the matrix gelatinases MMP2 and MMP9 are expressed in the adult songbird HVC, but that the testosterone-regulated gelatinase activity of the HVC microvascular endothelium is comprised by MMP2. Together, these observations suggest that VEGF specifically induces MMP2 production by brain microvascular endothelial cells, and that testosterone's induction of MMP2 activity in HVC is effected through the regionally restricted androgenic induction of VEGF, and the endothelial reception thereof.

\section{The androgenic induction of MMP2 mRNA follows that of VEGF and VEGFR2}

The testosterone-associated increase in HVC gelatinase in vivo, as well as its VEGF-triggered counterpart in endothelial cell culture, indicated that gelatinase enzymatic activity was regulated by testosterone, or more directly by VEGF, acting as its downstream effector. However, the enzymatic activity of the MMP gelatinases is potentially regulated at a variety of levels, including not only their direct transcription and translation, but also the proteolytic processing of their pro- forms, and cross-inhibition by TIMPs (tissue inhibitors of the matrix metalloproteinases). To identify the most proximal level of gelatinase regulatory control, we thus asked whether MMP expression was transcriptionally regulated by testosterone. To this end, we used degenerate PCR to amplify fragments of canary MMP2 and MMP9 from canary ovary cDNA, chosen as a likely rich source of gelatinase mRNAs. Primers were chosen from conserved regions of aligned chicken, turkey, and mouse MMP2 and MMP9 sequences. By this means, we cloned a 1471 bp canary MMP2 fragment that corresponded to bases 270-1744 of the chicken MMP2 gene (91\% homology to chicken, $78 \%$ to human), and contained both of the zinc binding domains $(\mathrm{ZnMc})$ and all three fibronectin type II repeats of the MMP2 gene (sequence provided via GenBank accession number EF408252). In addition, we cloned a 1044 bp MMP9 segment corresponding to bases 601-1386 and 1441-1569 of the chicken MMP9 gene (88\% homology); this clone contained the $\mathrm{FN} 2$ repeats and the C-terminal ZnMc domain of MMP9, but lacked the N-terminal ZnMc (GenBank accession number EF408253).

The derived sequence information then allowed us to use realtime PCR to analyze the temporal profiles of androgen-induced MMP2 and MMP9 mRNA expression, when assessed 4 and $8 \mathrm{~d}$ after testosterone. RT-PCR revealed that MMP9 mRNA levels were unaffected by testosterone. In contrast, MMP2 mRNA levels rose significantly within $4 \mathrm{~d}$ of testosterone treatment, and more than doubled by $8 \mathrm{~d}$ (Fig. 3). We concurrently assessed the androgen-dependent induction of both VEGF and its receptor VEGFR2 within HVC, and confirmed that their mRNAs rose within $4 \mathrm{~d}$ of testosterone treatment, as we had previously reported (Fig. 3). Thus, testosterone triggered the local HVC transcriptional activation of MMP2 synthesis, according to a time course that closely followed that of androgen-induced VEGF synthesis and release in HVC.

\section{MMP activation is required for testosterone-induced angiogenesis in $\mathrm{HVC}$}

On the basis of the temporal and spatial increased MMP activity of testosterone-stimulated adult female HVC, we asked whether

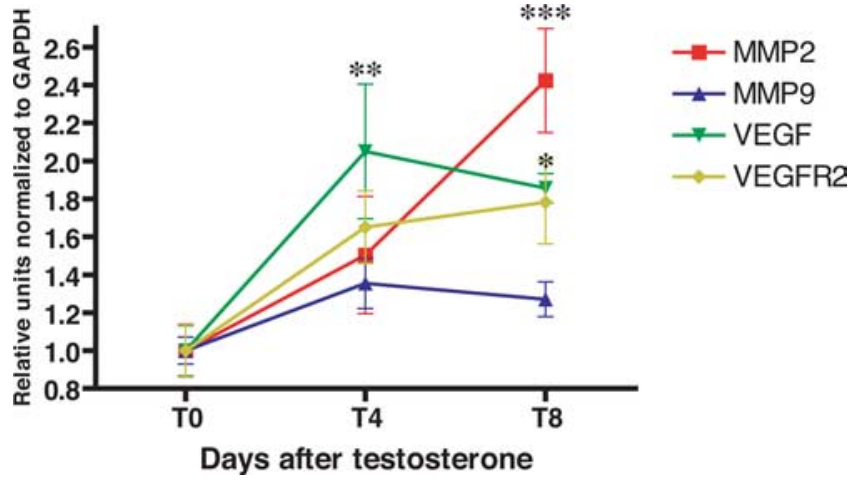

Figure 3. Testosterone treatment stimulated MMP2 transcription in vivo. Quantitative RTPCR of HVC $m$ RNA derived from testosterone-treated birds revealed that MMP2 levels rose by $4 \mathrm{~d}$ (T4) after testosterone and had at least doubled by $8 \mathrm{~d}$; in contrast, MMP9 levels were not affected by testosterone treatment. ${ }^{*} p<0.05$; ${ }^{* *} p<0.01$; ${ }^{* * *} p<0.001$ by ANOVA with Bonferroni $t$ tests.

MMP activation was causally associated with testosteronestimulated neovascularization and neuronal recruitment. To this end, we first assessed whether testosterone-induced MMP activity in HVC might be inhibited using SB-3CT, a potent thiirane inhibitor of the MMP2 and MMP9 gelatinases (Brown et al., 2000; Gu et al., 2005). In an initial dose-optimization pilot study, we established that daily systemic administration of SB-3CT via intrapectoral injection of $1 \mathrm{mg} / \mathrm{bird}$, or $50 \mathrm{mg} / \mathrm{kg}$ (i.m.), was sufficient to abolish demonstrable gelatinase activity as assessed by in situ zymography of the testosterone-treated HVC. Specifically, the slide zymograms revealed that SB-3CT suppressed testosterone-induced MMP activity in a dose-dependent manner, such that at $50 \mathrm{mg} / \mathrm{kg}$, HVC gelatinase activity was scarcely detectable (Fig. 4A-C). Both surface plot analysis (Fig. 4D-F) and pixel intensity-based distribution histograms (Fig. $4 G-I$ ) confirmed significant reductions in gelatinase-associated fluorescence in HVC microvessels, as a function of SB-3CT dose. Furthermore, this dose of SB-3CT exhibited no evident systemic toxicity, after as long as 3 weeks of daily administration.

On this basis, a cohort of 12 birds was then given SILASTIC implants containing either testosterone or nothing (empty SILASTIC controls), and then injected with either SB-3CT (1 mg/ bird/d, i.m.) or vehicle (20\% DMSO, 60\% PEG in sterile water) for $9 \mathrm{~d}$. This design yielded four groups of three birds each, all of which were injected twice daily throughout with BrdU (50 mg/ $\mathrm{kg}$, every $12 \mathrm{~h}, \mathrm{i} . \mathrm{m}$.) to label newly generated cells. The canaries were killed on day 10, and their brains were removed and cryosectioned at $14 \mu \mathrm{m}$ into 10 series of slides, such that consecutive slides within each series were $140 \mu \mathrm{m}$ apart. Adjacent sections in consecutive series were then stained for either BrdU and laminin or the estrogen receptor, the latter using monoclonal antibody (MAb) H222 $\gamma$ (Barami et al., 1994), while a third series was concurrently analyzed by in situ zymography. This design allowed us to compare the HVC endothelial labeling indices of birds as a dual function of testosterone and SB-3CT treatment (Fig. 5A). We found that testosterone-treated birds injected with a vehicle control exhibited an HVC endothelial mitotic index of $14.1 \pm$ $1.8 \%$ (mean $\pm \mathrm{SE}, n=3 \mathrm{birds}$; data represent $416 \mathrm{BrdU}^{+} / \mathrm{lami}-$ nin $^{+}$cells among 2895 pooled laminin ${ }^{+} /$DAPI $^{+}$cells) (Fig. $5 \mathrm{~B}, \mathrm{C})$. In contrast, the endothelial mitotic index of testosteronetreated birds treated with SB-3CT fell by over half, to $6.5 \pm 0.7 \%$ $\left(n=3 ; 218 \mathrm{BrdU}^{+} /\right.$laminin $^{+}$cells among 3386 laminin $^{+} /$ $\mathrm{DAPI}^{+}$endothelial cells) $\left(F_{(1,8)}=50.75\right.$ by two-way ANOVA covarying testosterone and SB-3CT treatment; overall $p<$ 

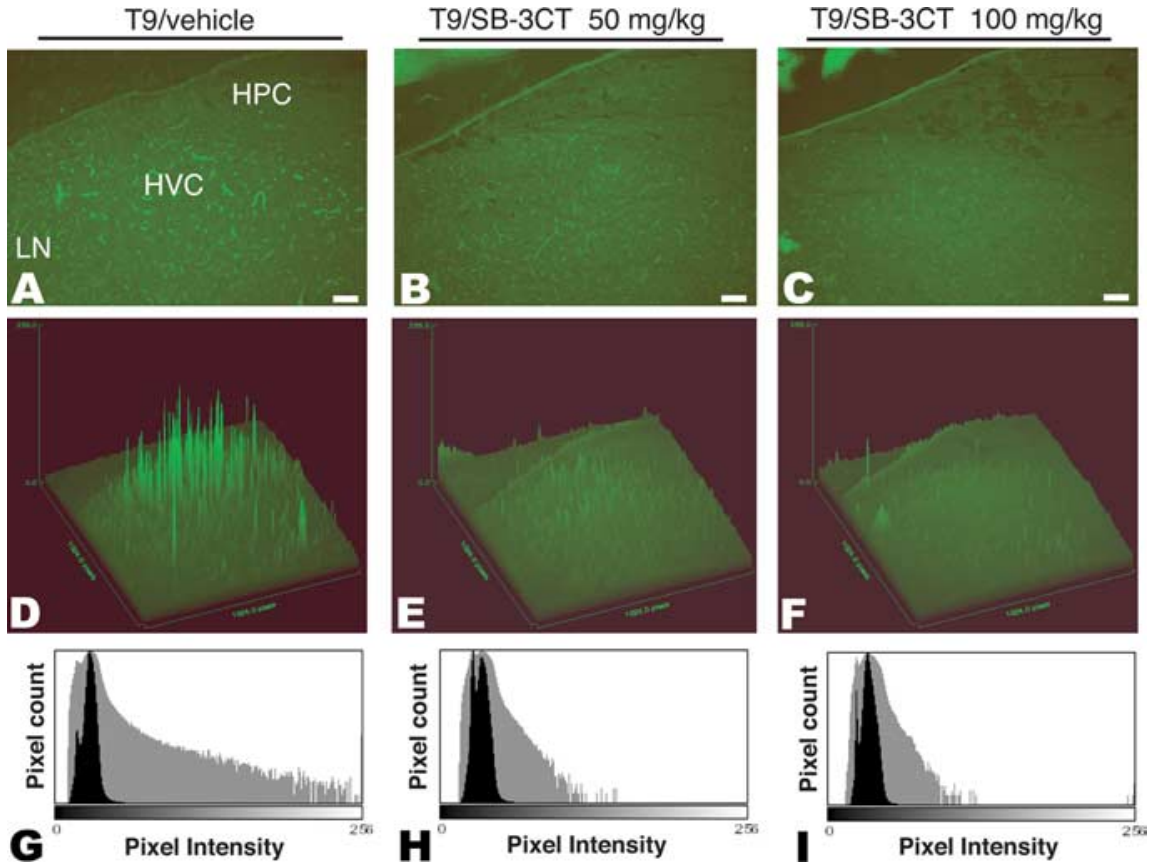

Figure 4. Testosterone-induced HVC MMP activity is blocked by the MMP2/9 inhibitor SB-3CT. A-C, For $9 \mathrm{~d}$ after testosterone implantation, birds were given vehicle $(\boldsymbol{A})$, the MMP2/9 inhibitor SB-3CT at $50 \mathrm{mg} / \mathrm{kg}(\boldsymbol{B})$, or SB-3CT at $100 \mathrm{mg} / \mathrm{kg}(\boldsymbol{C})$. On the ninth day (T9), the birds were killed, and their degree of HVC gelatinase inhibition was assessed by in situ zymography. $\boldsymbol{D}-\boldsymbol{F}$, Surface plot analysis of signal intensity using ImageJ; $\mathbf{D}-\boldsymbol{F}$ individually correspond to $\boldsymbol{A}-\boldsymbol{C}$. $\mathbf{G}-\boldsymbol{I}$, Distribution histogram for pixel intensity; $\mathbf{G}-\mathbf{I}$ correspond to $\boldsymbol{A}-\boldsymbol{C}$. Scale bars, $100 \mu \mathrm{m}$.

0.0001, as was post hoc Bonferroni $t$ test comparison of endothelial labeling index in testosterone-treated birds given SB-3CT vs vehicle). Thus, pharmacological inhibition of MMP2/9 gelatinase activity substantially reduced testosterone-induced angiogenesis (Fig. 5D). Importantly, SB-3CT exhibited no significant effect on baseline endothelial mitosis in otherwise untreated birds, because the endothelial labeling index of SB-3CT-treated null controls $\left(4.1 \pm 1.0 \%, n=3 ; 129 \mathrm{BrdU}^{+} /\right.$laminin $^{+}$cells among 3183 laminin ${ }^{+} / \mathrm{DAPI}^{+}$endothelial cells) did not differ significantly from their vehicle treated counterparts $(2.6 \pm 0.4 \%, n=3,64$ $\mathrm{BrdU}^{+} /$laminin $^{+}$among 2417 laminin $^{+} / \mathrm{DAPI}^{+}$endothelial cells).

\section{MMP activation is required for testosterone-induced neuronal recruitment}

We next asked whether MMP2-dependent angiogenesis and vascular expansion were required for neuronal addition to HVC; to this end, we asked whether the inhibition of HVC gelatinase activity by SB-3CT would result in the reduction of neuronal recruitment to HVC. We thus assigned another set of 161 -year-old female canaries to four treatment groups ( $n=4$ /group): (1) no hormone/vehicle; (2) no hormone/SB-3CT; (3) testosterone/vehicle; (4) testosterone/SB-3CT. Beginning on day 1 of the study, the birds were injected once daily with either SB-3CT (1 mg/bird, i.m.) or its vehicle (20\% DMSO/60\% PEG-200/20\% water). The birds were implanted with either testosterone or empty SILASTICs on day 2, at which point we initiated twice daily injections of BrdU (50 mg/kg, i.m.). Treatment with SB-3CT/BrdU was continued through day 25 , and the birds were killed on day 32 . Their brains were removed and then cryosectioned as noted at $14 \mu \mathrm{m}$. At $140 \mu \mathrm{m}$ intervals, two serial sections were respectively immunostained for estrogen receptor, to optimally localize HVC, and $\mathrm{BrdU} / \mathrm{Hu}$ to estimate the incidence of neuronal addition therein.
For each of the 16 birds, the ratio of $\mathrm{Hu}^{+} /$ $\mathrm{BrdU}^{+}$cells to all $\mathrm{Hu}^{+}$neurons within the ER-defined borders of HVC was determined, bilaterally.

We found that MMP inhibition was associated with a significant drop in HVC neuronal recruitment (Fig. $5 E-G$ ). In testosterone-treated controls injected only with vehicle, the BrdU-labeling index of $\mathrm{Hu}$-defined HVC neurons was $2.06 \pm$ $0.48 \%\left(n=5\right.$ birds; $333 \mathrm{BrdU}^{+} / \mathrm{Hu}^{+}$cells among a total sample of $16,107 \mathrm{Hu}^{+}$neurons). In contrast, testosterone-treated birds given SB-3CT exhibited a neuronal labeling index of $1.08 \pm 0.22 \%(n=6 ; 202$ $\mathrm{BrdU}^{+} / \mathrm{Hu}^{+}$among $18,802 \mathrm{Hu}^{+}$neurons), representing a $47 \%$ reduction in neuronal labeling index attributable to SB3CT treatment $\left(F_{(1,15)}=13.6\right.$ by two-way ANOVA covarying testosterone and SB3CT treatment, overall $p=0.0022 ; p<$ 0.01 for post hoc Bonferroni $t$ test comparison of neuronal labeling index in testosterone-treated birds given SB-3CT vs vehicle). Among controls not given testosterone, birds given SB-3CT alone exhibited a neuronal labeling index of $0.35 \pm 0.02 \%$ $\left(n=4,56 \mathrm{BrdU}^{+} / \mathrm{Hu}^{+}\right.$cells among a total sample of $15,982 \mathrm{Hu}^{+}$neurons), whereas additional controls given vehicle only exhibited a similarly low neuronal labeling index of $0.46 \pm 0.12 \%$ ( $n=4,68 \mathrm{BrdU}^{+} / \mathrm{Hu}^{+}$cells among $14,585 \mathrm{Hu}^{+}$neurons). Overall, SB-3CT's profound suppression of testosterone-induced neuronal addition strongly suggests that MMP activation is a critical checkpoint for androgen-associated neuronal recruitment to the adult HVC.

\section{Discussion}

These experiments demonstrate that testosterone-induced gelatinase activity is a necessary prerequisite to both angiogenesis and neurogenesis in the adult HVC, the neurogenic vocal control center of the songbird brain. Testosterone appeared to act through VEGF as a paracrine intermediate, in that VEGF exposure was sufficient to induce isolated canary forebrain endothelial cells to express MMP, whereas testosterone alone was associated with neither the transcriptional nor enzymatic induction of gelatinase activity in vitro. In vivo, the induced gelatinase activity was specifically represented by a canary homolog of MMP-2, in that MMP2 mRNA levels doubled within $8 \mathrm{~d}$ of testosterone, whereas MMP9 mRNA levels were unaltered. Importantly, the induction of MMP2 appeared to be a necessary antecedent to both angiogenesis and neuronal recruitment, in that the gelatinase-specific inhibitor SB-3CT substantially suppressed both angiogenesis and neurogenesis in HVC. These observations suggest that the testosterone-triggered, VEGF-mediated induction and activation of MMP2 might comprise a critical checkpoint in regulating the androgenic induction of angiogenesis and neuronal recruitment in the adult songbird HVC.

The apparent requirement for gelatinase activity to neuronal addition to the HVC suggests its necessity to the tissue remodeling that attends cell migration through adult brain parenchyma. Similar examples of the necessity of MMP activity to tissue remodeling have been elucidated both in response to hypoxic isch- 
emia, in which the gliovascular response to stroke has been shown to require both MMP activity and MMP-released VEGF (Zhao et al., 2006), and in association with glioma invasion, with which MMP2 and MMP9 activities have been causally associated (Yong et al., 2001; Rao, 2003). However, despite the involvement of the gelatinases in brain tissue responses to injury, and to tumor cell migration, no previous association had been made between gelatinase activity and the permissiveness to neuroblast migration and neuronal addition that characterizes neurogenic regions of adult brain parenchyma. In that context, the relative restriction of testosteroneinduced MMP2 activity to the neurogenic HVC, and the apparent necessity of that gelatinase activity to HVC neuronal recruitment, suggests that the lack of permissiveness to neuronal addition in otherwise non-neurogenic regions of the brain may reflect in part a physiological restriction on matrix gelatinase activation in those regions.

Besides permitting neuronal addition, androgen-stimulated gelatinase activity may serve to liberate matrix-bound VEGF and other angiogenic growth factors, and by so doing to jumpstart testosteroneinduced angiogenesis. Such a process of angiogenic growth factor release from previously stable tissue interstitium has already been demonstrated in tumor angiogenesis, in which tumor cell-derived gelatinase activity serves to release matrixbound VEGF, thereby initiating elaboration of the tumor vasculature (Bergers et al., 2000; Egeblad and Werb, 2002). Indeed, the androgenic stimulation of VEGF production in HVC, followed by VEGF-induced vascular MMP release, may establish a positive feedback by which the initial increment in VEGF transcription can be rapidly amplified. In particular, the MMP-mediated release of matrix-bound VEGF might be expected to locally liberate amounts of VEGF potentially much greater than those provided by its transcriptional induction. This MMP2-mediated amplification of VEGF availability might be expected to both accelerate and potentiate the angiogenic response to testosterone, an event that is in turn necessary for subsequent neuronal recruitment (Louissaint et al., 2002). By such means, androgen-mediated MMP activation might serve to dynamically regulate neuronal addition to the adult HVC.

The in vivo dependence of adult ventricular zone neurogenesis and parenchymal neuronal migration on endothelial MMP activation finds parallels in other stem cell niches, from which the migration of differentiated progeny has been related to MMP activation ( $\mathrm{Vu}$ and Werb, 2000; Heissig et al., 2002). In these systems, gelatinase activity may permit parenchymal cell transit not only through matrix degradation and the liberation of permissive cognate cytokines, but also by means of liberating soluble ligands from cells within the local environment, that may influence immigrating migrants. For instance, Heissig et al. (2002) have reported that the mobilization of bone marrow hematopoi- etic stem cells is critically dependent on MMP9 activation; gelatinase in this case causes the proteolytic shedding of kit-ligand, and a consequent mobilization of c-kit responsive progenitors, which then transit from quiescent to proliferative niches in the bone marrow. Similar mechanisms may be operative in the MMP-mediated invasion of basement membranes by mesenchymal stem cells (Ries et al., 2007). Indeed, the release of stem cell progeny from adult germinative niches appears to share a dependence on MMP activation with the parenchymal invasion of tumor cells, as has been noted in both CNS and systemic malignancies [for review, see Egeblad and Werb (2002) and Overall and Lopez-Otin (2002)].

Together, these findings indicate that testosterone-induced endothelial MMP2 activation is a prerequisite for the successful addition of newly generated neurons to the adult HVC, and indicate the critical importance of MMP activity to the migration of new neurons from their germinative niche in the ventricular zone, to their parenchymal destinations in the forebrain. This mechanism is schematized in Fig. 6, which highlights the role of MMP2 activation in the cell-cell interactions that regulate gonadal steroid-associated angiogenesis and neurogenesis in the adult HVC. In the broader context of the regulatory framework within which gonadal steroid-associated angiogenesis and neurogenesis proceed in the adult HVC, MMP activation may be viewed as one of several rate-limiting checkpoints, which include the downregulation of $\mathrm{N}$-cadherin by newly generated neurons 


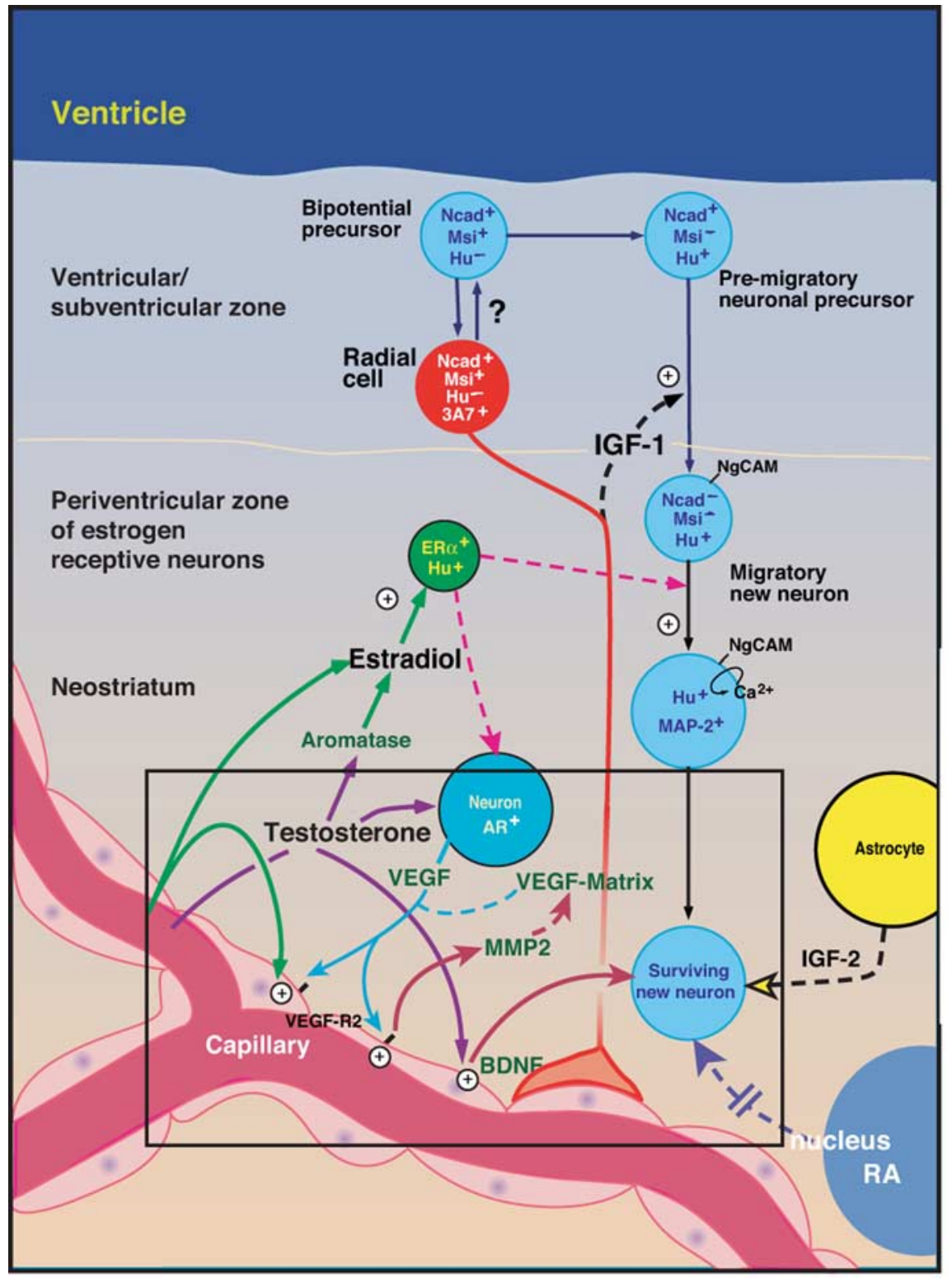

Figure 6. An orchestrated set of paracrine interactions mediates adult HVC neurogenesis. This schematic highlights the role of HVC MMP2 during testosterone-induced neuronal recruitment by the adult HVC. Together with the gonadal steroid-mediated induction of both VEGF and its receptor VEGFR2/flk1, which leads in turn to angiogenesis and BDNF production by the activated microvascular bed, the androgen-triggered vascular production of MMP2 appears to comprise a critical gate-keeping step, that establishes the permissiveness of the adult brain parenchyma to accept new neuronal immigrants (adapted in part from Louissaint et al., 2002).

(Barami et al., 1994), their activation of NgCAM-triggered calcium signaling (Goldman et al., 1996; Williams et al., 1999), and their serial support by IGF1, VEGF, and BDNF (Jiang et al., 1998; Rasika et al., 1999; Louissaint et al., 2002), which are individually necessary for, and which collectively serve to orchestrate, neuronal addition to the adult songbird brain. The progression through these checkpoints defines those regions of the adult songbird brain able to recruit and accept new neurons, and in so doing, establishes the parameters by which structural neuroplasticity may be dynamically regulated in the adult brain.

\section{References}

Alvarez-Buylla A (1992) Neurogenesis and plasticity in the CNS of adult birds. Exp Neurol 115:110-114.
Barami K, Iverson K, Furneaux H, Goldman P (1995) Early expression of $\mathrm{Hu}$ proteins by newly generated neurons in the adult avian forebrain. J Neurobiol 28:82-101.

Barami K, Kirschenbaum B, Lemmon V, Goldman SA (1994) $\mathrm{N}$-cadherin and Ng-CAM/8D9 are involved serially in the migration of newly generated neurons into the adult songbird brain. Neuron 13:567-582.

Bergers G, Brekken R, McMahon G, Vu T, Itoh T, Tmaki K, Tanzawa $\mathrm{K}$, Thorpe $\mathrm{P}$, Itohara $\mathrm{S}$, Werb Z, Hanahan D (2000) Matrix metalloproteinase- 9 triggers the angiogenic switch during carcinogenesis. Nat Cell Biol 2:737-744

Brown S, Bernardo M, Li Z, Kotra L, Tanaka Y, Fridman R, Mobashery S (2000) Potent and selective mechanism-based inhibition of gelatinases. J Am Chem Soc 122:6799-6800.

Descamps F, Martens E, Opdenakker G (2002) Analysis of gelatinases in complex biological fluids and tissue extracts. Lab Invest 82:1607-1611.

Egeblad M, Werb Z (2002) New functions for the matrix metalloproteinases in cancer progression. Nat Rev Cancer 2:163-175.

Frederiks W, Mook O (2004) Metabolic mapping of proteinase activity with emphasis on in situ zymography of gelatinases: review and protocols. J Histochem Cytochem 52:711-722.

Gahr M (1990) Delineation of a brain nucleus: comparisons of cytochemical, hodological, and cytoarchitectural views of the song control nucleus HVC of the adult canary. J Comp Neurol 294:30-36.

Goldman SA, Nottebohm F (1983) Neuronal production, migration, and differentiation in a vocal control nucleus of the adult female canary brain. Proc Natl Acad Sci USA 80:2390-2394.

Goldman SA, Williams S, Barami K, Lemmon V, Nedergaard M (1996) Transient coupling of $\mathrm{Ng}$-CAM expression to NgCAM-dependent calcium signaling during migration of new neurons in the adult songbird brain. Mol Cell Neurosci 7:29-45.

Gu Z, Cui J, Brown S, Fridman R, Mobashery S, Strongin A, Lipton S (2005) A highly specific inhibitor of MMP9 rescues laminin from proteolysis and neurons from apoptosis in transient focal cerebral ischemia. J Neurosci 25:6401-6408.

Heissig B, Hattori K, Dias S, Friedrich M, Ferris B, Hackett N, Crystal R, Besmer P, Lyden D, Moore M, Werb Z, Rafii S (2002) Recruitment of stem and progenitor cells from the bone marrow niche requires MMP-9 mediated release of kit-ligand. Cell 109:625-637.

Hidalgo A, Barami K, Iversen K, Goldman SA (1995) Estrogens and nonestrogenic ovarian influences combine to promote the recruitment and decrease the turnover of new neurons in the adult female canary brain. J Neurobiol 27:470-487.

Jarvis E, Güntürkün O, Bruce L, Csillag A, Karten H, Kuenzel W, Medina L, Paxinos G, Perkel DJ, Shimizu T, Striedter G, Wild JM, Ball GF, DugasFord J, Durand SE, Hough GE, Husband S, Kubikova L, Lee DW, Mello $\mathrm{CV}$, et al. (2005) Avian brains and a new understanding of vertebrate brain evolution. Nat Rev Neurosci 6:151-159.

Jiang J, McMurtry J, Niedzwiecki D, Goldman SA (1998) Insulin-like growth factor-1 is a radial cell-associated neurotrophin that promotes neuronal recruitment from the adult songbird ependyma/subependyma. J Neurobiol 36:1-15.

Leventhal C, Rafii S, Rafii D, Shahar A, Goldman SA (1999) Endothelial 
trophic support of neuronal production and recruitment from the adult mammalian subependyma. Mol Cell Neurosci 13:450-464.

Louissaint Jr A, Rao S, Leventhal C, Goldman SA (2002b) Coordinated interaction of neurogenesis and angiogenesis in the adult songbird brain. Neuron 34:945-960.

Nottebohm F (2002) Why are some neurons replaced in adult brain? J Neurosci 22:624-628.

Overall C, Lopez-Otin C (2002) Strategies for MMP inhibition in cancer: innovations for the post-trial era. Nat Rev Cancer 2:657-672.

Rao J (2003) Molecular mechanisms of glioma invasiveness: the role of proteases. Nat Rev Cancer 3:489-501.

Rasika S, Alvarez-Buylla A, Nottebohm F (1999) BDNF mediates the effects of testosterone on the survival of new neurons in an adult brain. Neuron 22:53-62.

Reiner A, Perkel D, Bruce L, Butler A, Csillag A, Kuenzel W, Medina L, Paxinos G, Shimizu T, Striedter G, Wild M, Ball GF, Durand S, Güntürkün O, Lee DW, Mello CV, Powers A, White SA, Hough G, Kubikova L, et al. (2004) Revised nomenclature for avian telencephalon and some related brainstem nuclei. J Comp Neurol 473:377-414.

Ries C, Egea V, Karow M, Kolb H, Jochum M, Neth P (2007) MMP2, MT1MMP, and TIMP-2 are essential for the invasive capacity of human mes- enchymal stem cells: differential regulation by inflammatory cytokines. Blood 109:4055-4063.

Stokes T, Leonard C, Nottebohm F (1976) The telencephalon, diencephalon and mesencephalon of the canary, Serinus canaria, in stereotaxic coordinates. J Comp Neurol 156:337-374.

Vu T, Werb Z (2000) Matrix metalloproteinases: effectors of development and normal physiology. Genes Dev 14:2123-2133.

Wang X, Lee S-R, Arai K, Lee S-J, Tsuji K, Rebeck G, Lo EH (2003) Lipoprotein receptor-mediated induction of matrix metalloproteinase by tissue plasminogen activator. Nat Med 9:1313-1317.

Williams S, Leventhal C, Lemmon V, Nedergaard M, Goldman SA (1999) Estrogen promotes the initial migration and inception of NgCAMdependent calcium-signaling by new neurons of the adult songbird brain. Mol Cell Neurosci 13:41-55.

Yong VW, Power C, Forsyth P, Edwards D (2001) Metalloproteinases in biology and pathology of the nervous system. Nat Rev Neurosci 2:502-511.

Zhao B-Q, Wang S, Kim H-Y, Storrie H, Rosen B, Mooney D, Wang X, Lo EH (2006) Role of matrix metalloproteinases in delayed cortical responses after stroke. Nat Med 12:441-445. 